\title{
The Effect of Communication Skills Training for parents on Adolescent Female Students' Self-Esteem
}

\author{
Narges Nasirinia ${ }^{1}$, Robabeh Memarian ${ }^{1 *}$, Aliakbar Rasekhi ${ }^{1}$ \\ 1. Faculty of Medical Sciences, Tarbiat Modares University, Tehran, Iran
}

Received: 24 August 2020

Accepted for publication: 2 March 2021

[EPub a head of print-10 March 2021]

Payesh: 2021; 20 (2): 191-199

\begin{abstract}
Objective (s): The association between self-esteem and the process of mental development of individuals and mental health is well established. In adolescence, the role of parents and their skills in communicating is very sensitive and vital. The purpose of this study was to assess the effect of parents' communication skills training on the self-esteem of adolescent female students.

Methods: This was a quasi-experimental study that conducted in one of the state high schools in Damavand, Iran in 2019. The sample consisted of 77 adolescent girls and their parents who were assigned to two groups: intervention and control. Parents in the intervention group received 16 training sessions in a group pf 10 participants. The control group received nothing. In both groups students completed a self-esteem questionnaire (Cooper-Smith questionnaire) at two points in time: before intervention and three months after the intervention. The data were analyzed by Wilcoxon, Mann-Whitney and analysis of covariance using SPSS22 software.

Results: Both groups were similar in most characteristics and at baseline self-esteem score did not differ significantly between two groups $(\mathrm{p}=0.49)$. However, after the intervention, there was a significant difference between the experimental and control groups according to analysis of covariance $(\mathrm{p}=0.001)$.

Conclusion The findings suggest parents' communication skills training could be effective in improving adolescents' selfesteem.
\end{abstract}

Key Words: Adolescent girl, Communication skills, High school, Parents, Self-esteem

\footnotetext{
* Corresponding author: Faculty of Medical Sciences, Tarbiat Modares University, Tehran, Iran

E-mail: memari_r@modares.ac.ir
} 


\title{
تاثير برنامه آموزشى مهارتهاى ارتباطى والدين بر ميزان عزتنفس دانش آموزان دختر نوجوان
}

\author{
نر كس نصيرى نيا'، ربابه معماريان '، على اكبر راسخى' \\ I. دانشكده علوم يزشكى، دانشعاه تربيت مدرس، تهران، ايران

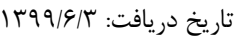

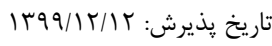

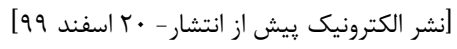

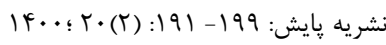

مقدمه: عزتنفس قطعى ترين عامل در روند رشد روانى افراد و يكى از معيارهاى سلامت روان مىباشد. در دوره نوجوانى نقش والدين و مهارت

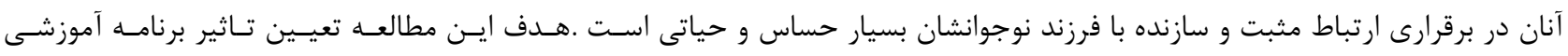

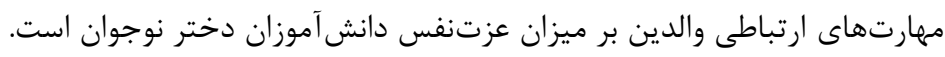

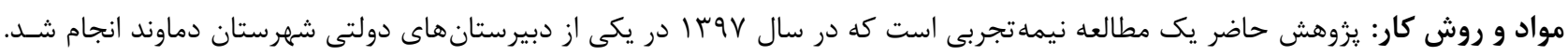

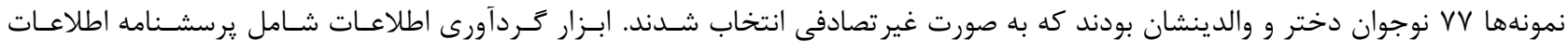

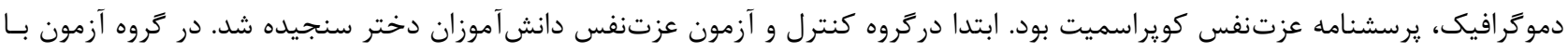

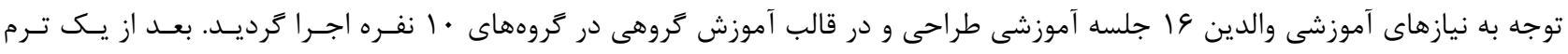

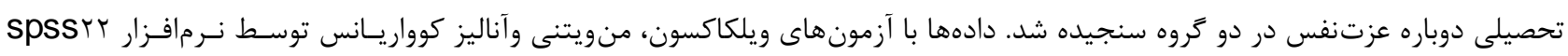

تجزيهوتحليل شدند.

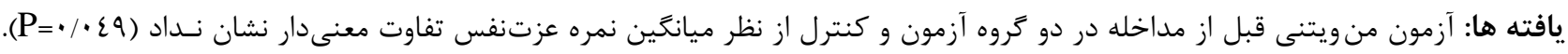

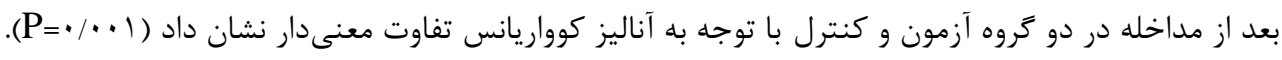

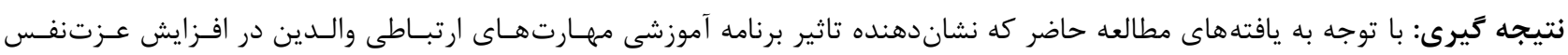

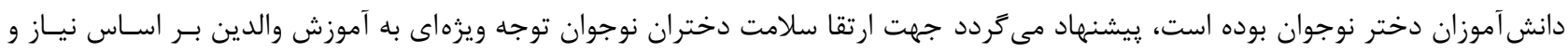
خصوصيات دوران نوجوانى شود.

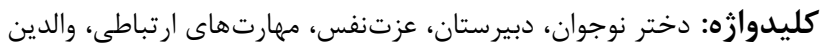


به طور معمول عزتتفس تا رسيدن بـهـ سـن نوجـوانى بــهـ تـدريج

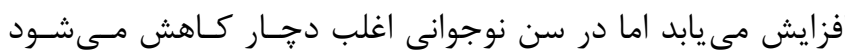

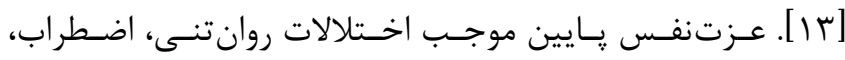

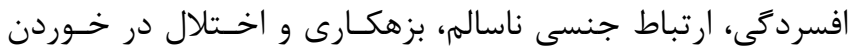

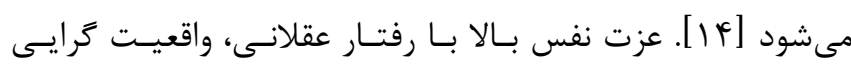

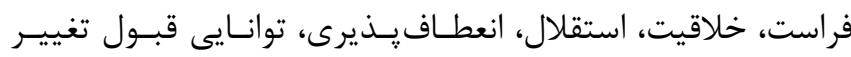

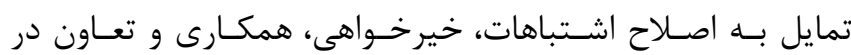

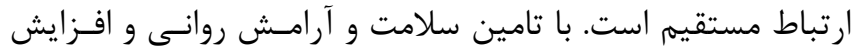

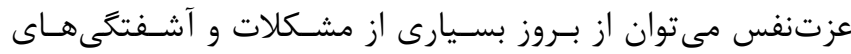

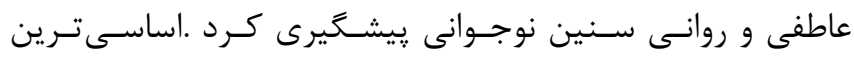

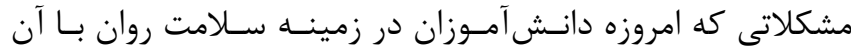

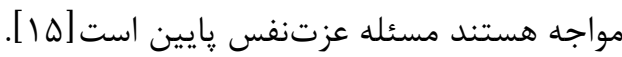

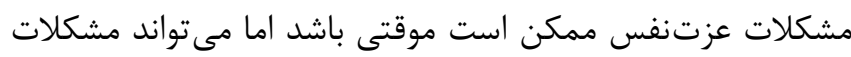

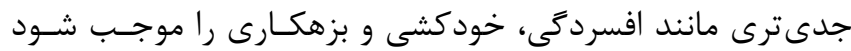

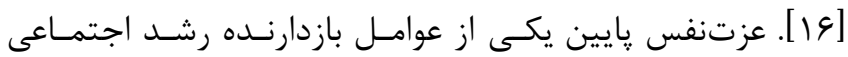

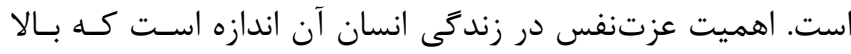

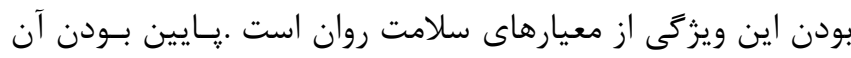

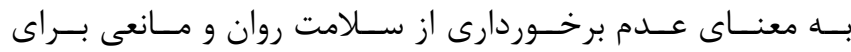

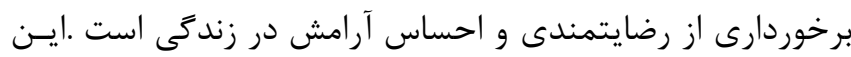

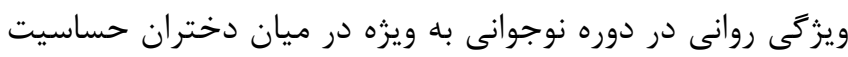
فراوانى دارد [19].

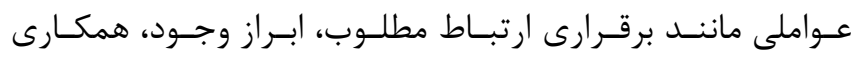

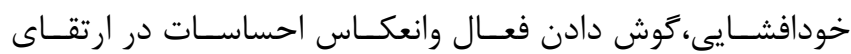

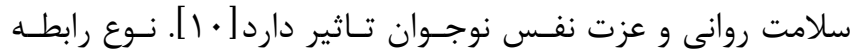

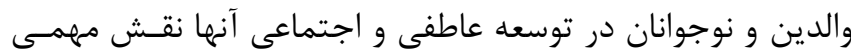

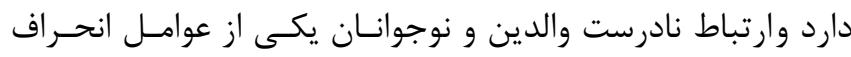

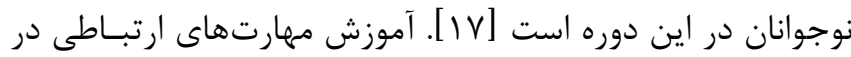

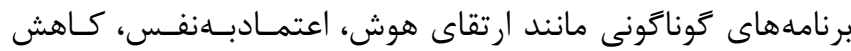

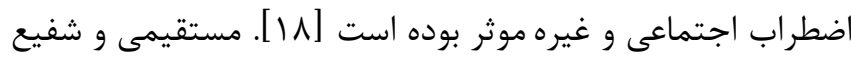

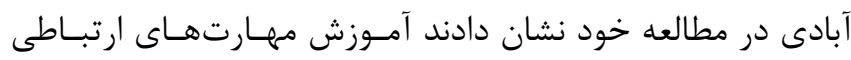

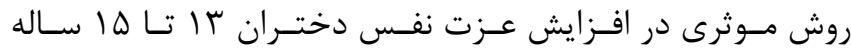

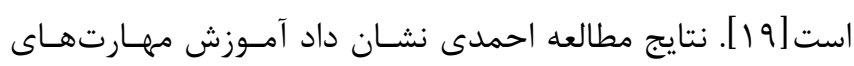

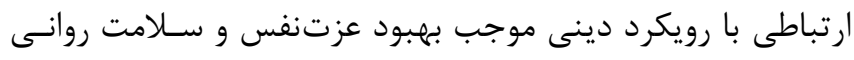

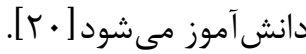

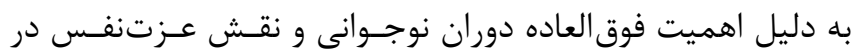

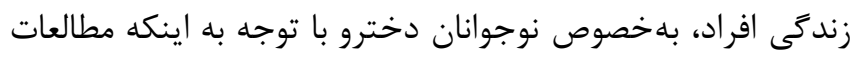

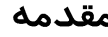

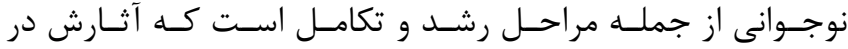

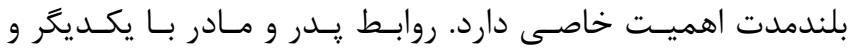

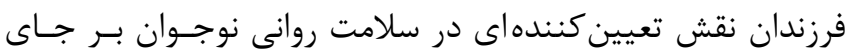

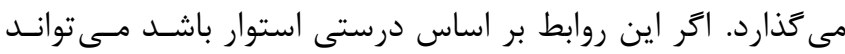

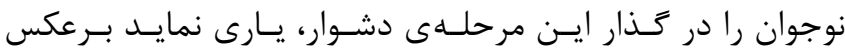

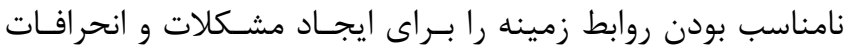

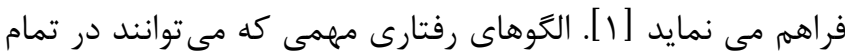

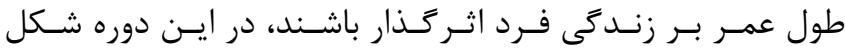

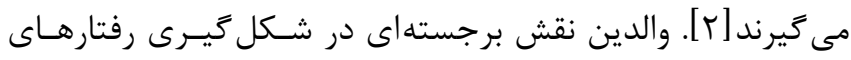
سازنده و مخرب فرزندان دارند [ب].

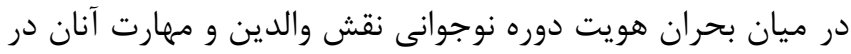

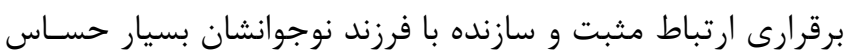

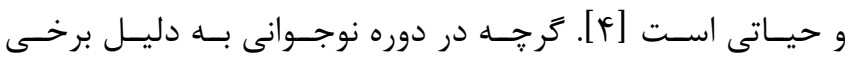

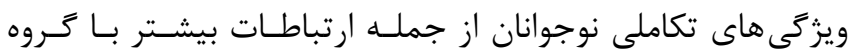

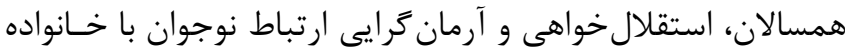

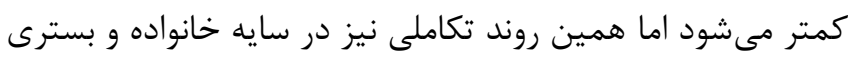

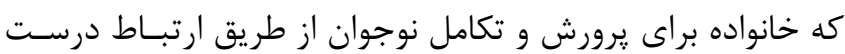

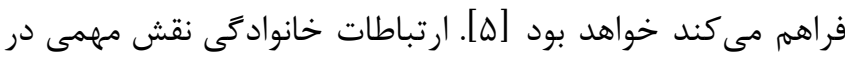

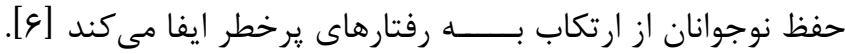

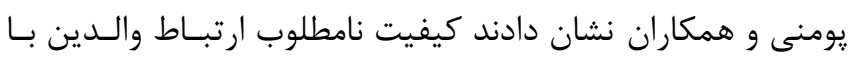
نوجوان با افزايش مشكلات در سـلامت رفتـارى و روانسى در بــين

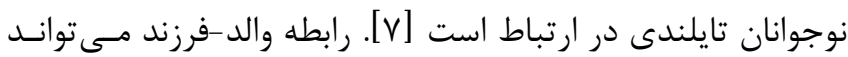

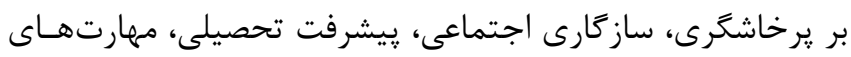

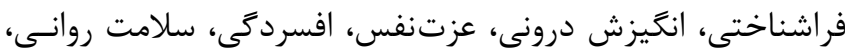

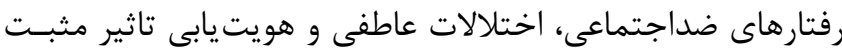

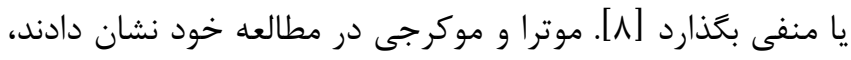

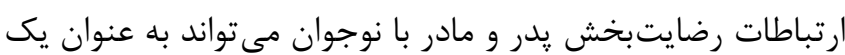

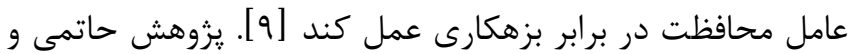

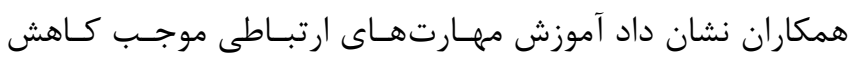

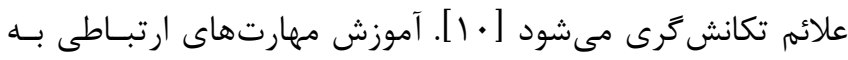
والدين در كاهش يرخاشكرى، استرس و تعارض والدين و افزايش

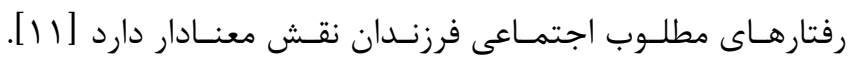

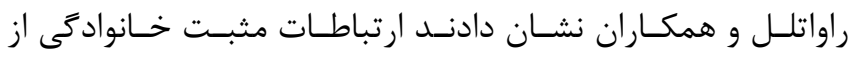

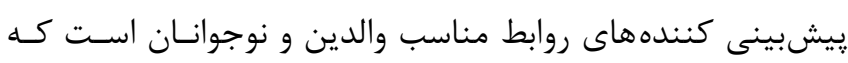

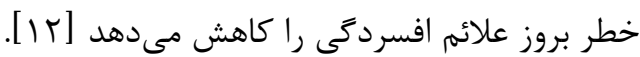


ليست برقرارى ارتباط والدين شامل ك ا اقدامى اسـت كـه والـدين

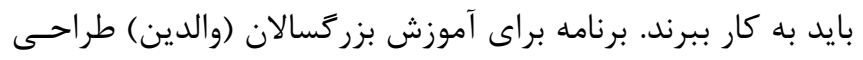

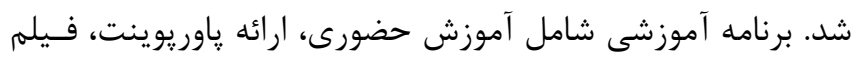

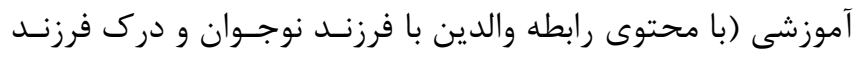

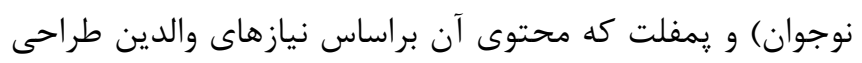

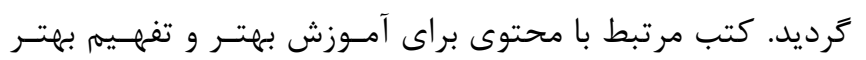

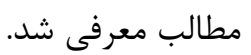

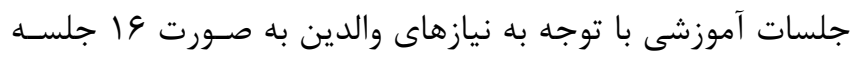

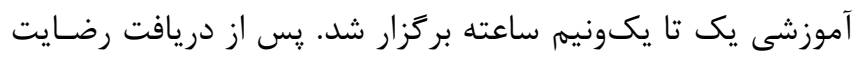

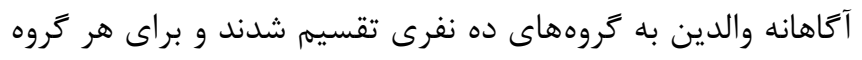

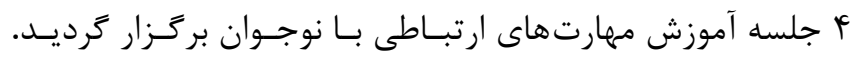
موضوعات بحث شده در جلسات شامل اهميت ارتباط بـانـان نوجــوان،

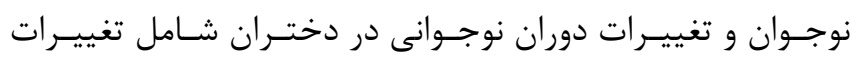

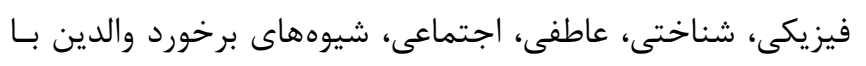

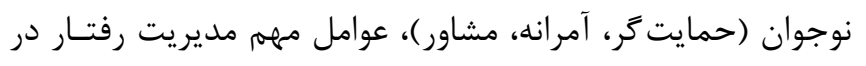

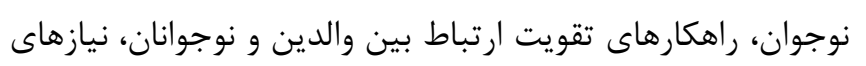

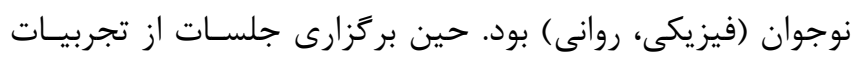

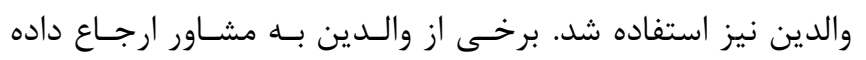

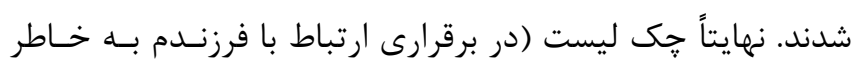

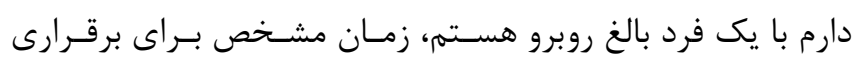

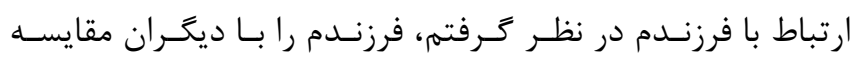

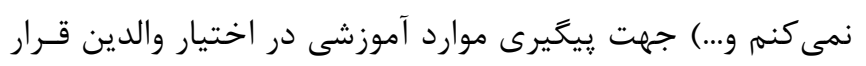

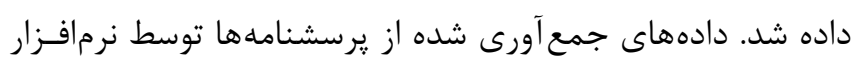

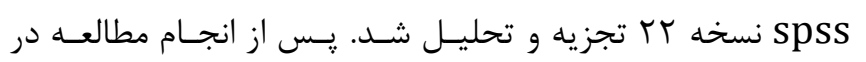

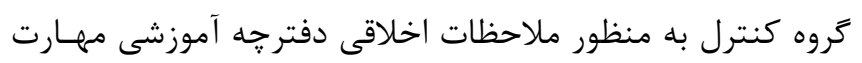

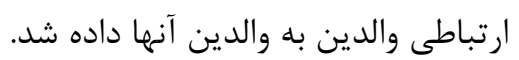

يافتهها

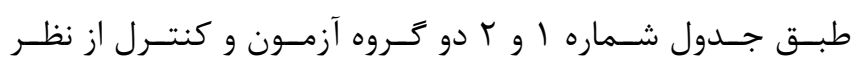

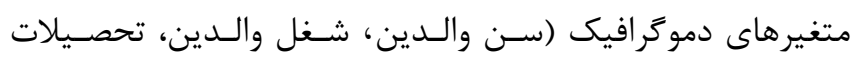

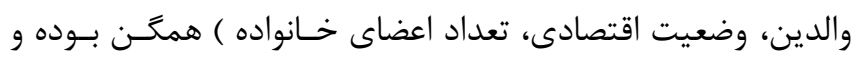

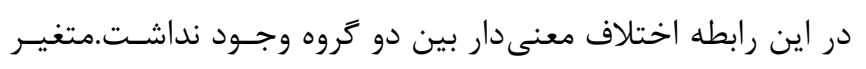

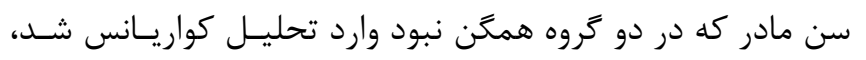

$$
\text { اما ضريب كوجكى داشت و معنى دار نبود. }
$$

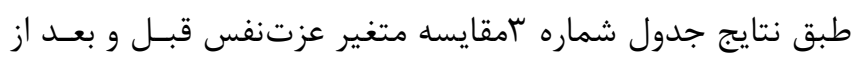

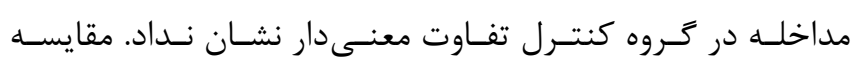

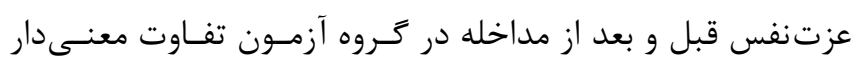

در زمينه مهارت ارتباط با نوجوان بر روى والدين انجام نشــده، ايـن

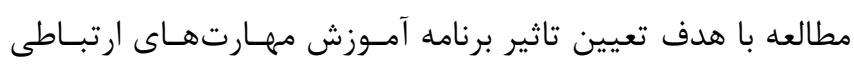
والدين بر ميزان عزتنفس دانش آموزان دختر نوجوان انجام شد.

\section{مواد و روش كار}

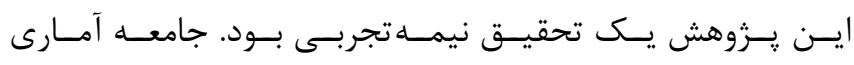

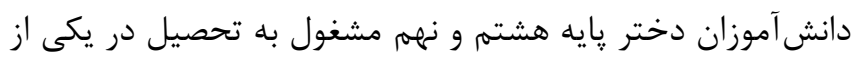

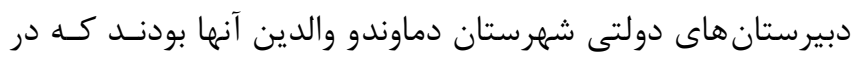

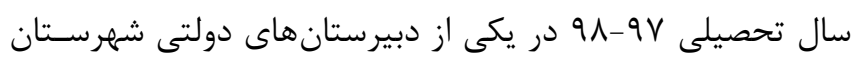

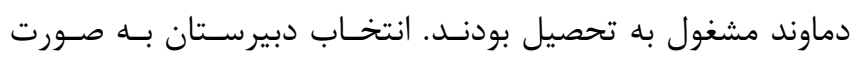

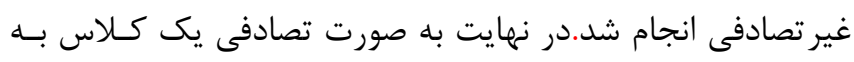

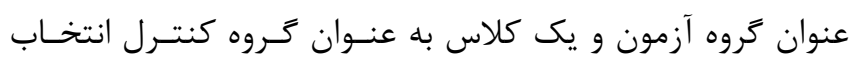

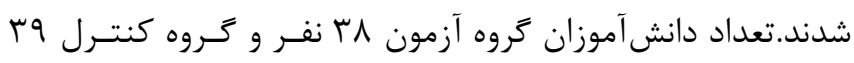

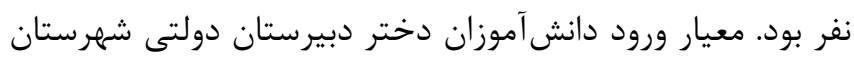

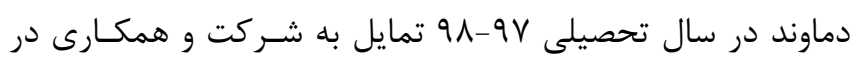

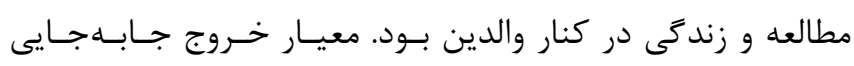

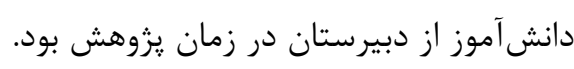
دو يرسشنامه جهت گردآورى اطلاعات مورد استفاده قرار كرفت:

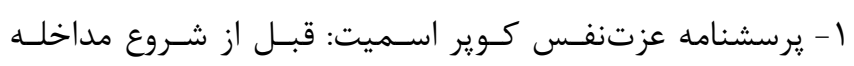

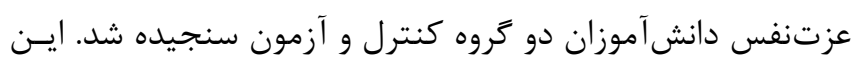

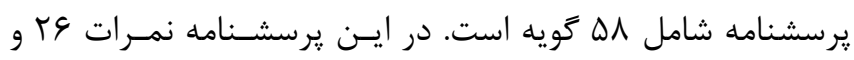

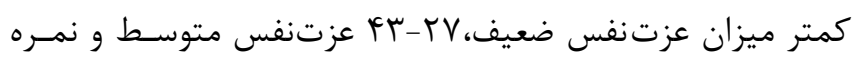

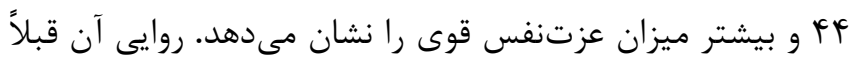

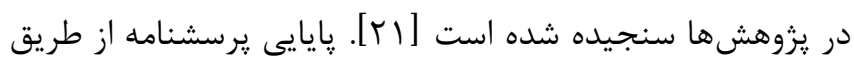

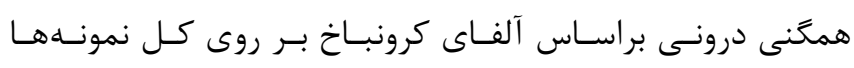

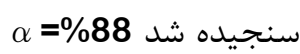
r- يرسشنامه اطلاعات دموكر افيك خانواده و دانش آموزان: شـامل

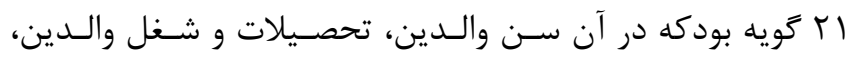

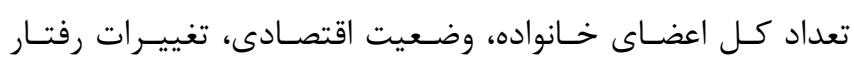

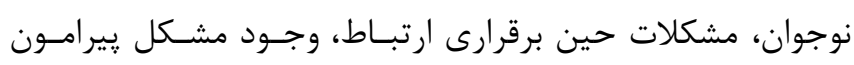

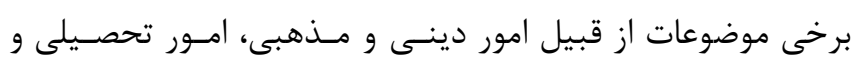

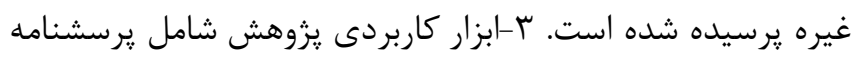

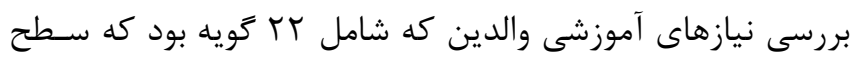

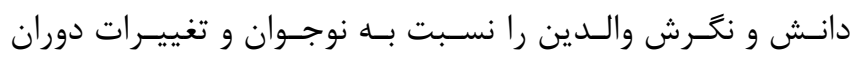

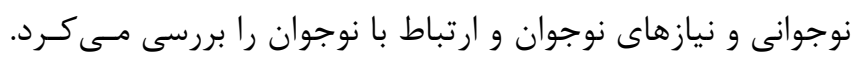

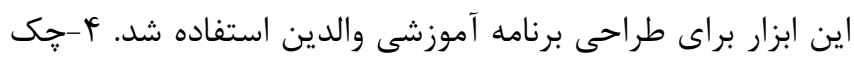


مقايسه شده اند. براى بررسى اثر مداخله بر "اعزتنفس" از تحليل

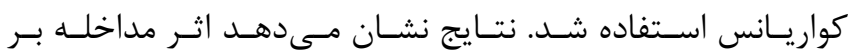

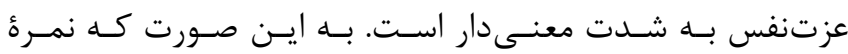

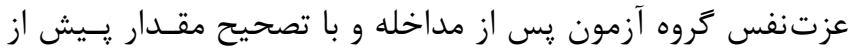

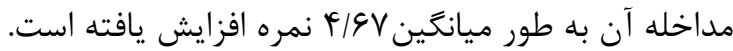

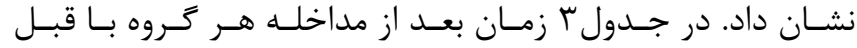

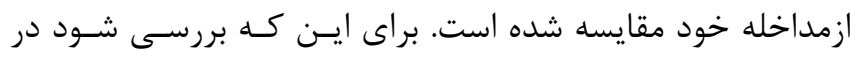

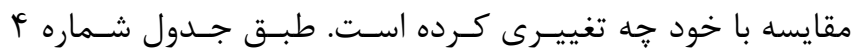
متغير عزتنفس قبل از مداخله در دو كروه - معنى دار نيست- دو

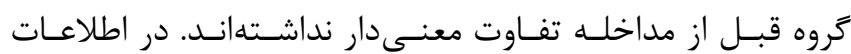

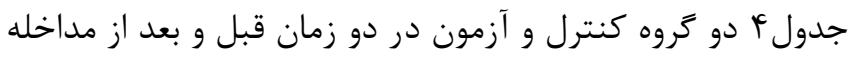

\begin{tabular}{|c|c|c|c|c|c|c|c|}
\hline \multirow{3}{*}{$\begin{array}{l}\text { p-value } \\
\text { (نام آزمون) }\end{array}$} & & & & \multicolumn{4}{|c|}{ جدول ا: ميانكَين سن والدين دانش آموزان دختر نوجوان در دو كروه آزمون وكنترل } \\
\hline & آزمون & & & كنترل & & & \\
\hline & انحراف معيار & ميانَين & تعداد & انحر اف معيار & ميانكَين & تعداد & \\
\hline تى مستقل & $\Delta / 11$ & re/Tr & ru & $\mathrm{F} / \mathrm{A \Lambda}$ & $4 \% / Q 9$ & rq & بدر \\
\hline تى مستقل & ه/lT & $4 \cdot 1 \wedge 9$ & rی & $\mathrm{r} / \mathrm{\Lambda}$ & $r N / \Delta)$ & rq & مادر \\
\hline
\end{tabular}

جدول r: توزيع فراوانى مطلق و نسبى متغيرهاى دموكَرافيك در دو كروه آزمون و كنترل

\begin{tabular}{|c|c|c|c|c|c|c|c|}
\hline & & & كنترل & & آزمون & & \\
\hline $\mathrm{p}$-value & نوع ازمون & فراوانى نسبى & فراوانى مطلق & فراوانى نسبى & فراوانى مطلق & دموكرافيك & \\
\hline \multirow[t]{5}{*}{.191} & $x^{2}$ & $V / V$ & $r$ & $\Delta / r$ & $r$ & بى سواد & تحصيلات مادر \\
\hline & & $V / V$ & r & $10 / 1$ & 4 & ابتدايى & \\
\hline & & rN/Q & 10 & $r G / T$ & 1. & راهنمايى & \\
\hline & & $\psi_{1}$ & 19 & $e V / f$ & 11 & دييلم & \\
\hline & & $\Delta / 1$ & r & $\Delta / r$ & r & دانشكاهى & \\
\hline \multirow[t]{5}{*}{$\cdot / 4 \wedge$} & $x^{2}$ & $r / 9$ & 1 & $\cdot$ & . & بى سواد & تحصيلات پدر \\
\hline & & $1 V / 9$ & $v$ & $r N / 9$ & 11 & ابتدايى & \\
\hline & & $r \cdot / \Lambda$ & ir & $r F / T$ & וr & راهنمايى & \\
\hline & & il & 19 & re/r & 1. & دييلم & \\
\hline & & $V / V$ & r & $1 \cdot / 0$ & $r$ & دانشخاهى & \\
\hline \multirow[t]{4}{*}{$\cdot / \cdot \mathrm{VV}$} & $x^{2}$ & $\cdot$ & . & $r / 9$ & 1 & ضعيف & وضعيت اقتصادى \\
\hline & & $\forall \& / T$ & 11 & VI/I & tr & متوسط & \\
\hline & & 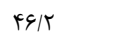 & 11 & $r M / l$ & $\wedge$ & خوب & \\
\hline & & $V / V$ & $r$ & $\Delta / r$ & r & عالى & \\
\hline \multirow[t]{5}{*}{.191} & $x^{2}$ & $r / 4$ & 1 & $r / 9$ & 1 & ك انفر & تعداد اعضاى خانواده \\
\hline & & $V / V$ & r & $\mid N / 4$ & v & ك انفر & \\
\hline & & $\Delta 1 / \pi$ & r. & $r 9 / \Delta$ & 10 & أ نفر & \\
\hline & & $r T / 1$ & 9 & $r \mu / V$ & 9 & 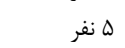 & \\
\hline & & $\mid Q / 4$ & 4 & $10 / 1$ & 4 & ع نفر و بالاتر & \\
\hline \multirow[t]{4}{*}{$\cdot / / V$} & $x^{2}$ & $\mid r / A$ & $\Delta$ & $1 / / 4$ & v & كاركر & شغل پدر \\
\hline & & $r \cdot 10$ & $\wedge$ & re/r & 1. & كارمند & \\
\hline & & $99 / \mathrm{V}$ & re & $q V / F$ & 11 & آزاد & \\
\hline & & $\cdot$ & . & $V / q$ & $r$ & ساير & \\
\hline \multirow[t]{2}{*}{$\cdot / \Delta V$} & $x^{2}$ & $9 \% / 9$ & $r v$ & $9 V / 4$ & rv & خانه دار & شغل مادر \\
\hline & & $\Delta / 1$ & r & $r / 9$ & 1 & كارمند & \\
\hline
\end{tabular}




\begin{tabular}{|c|c|c|c|c|c|}
\hline \multirow[t]{2}{*}{$\mathrm{p}$-value } & بعد & & ن و كنترل قبر & ق قبل & جدول \\
\hline & انحراف معيار & ميانكَين & انحراف معيار & ميانگين & \\
\hline $\begin{array}{l}\text { ويلكاكسون } \\
\text { و } 14\end{array}$ & N/9r & $\mu F / l r$ & N/AT & $r \Delta / \cdot \Delta$ & كنترل \\
\hline 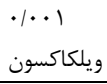 & $9 / 91$ & $r V / V F$ & $9 / 1$ & $r r / \Delta \Delta$ & آزمون \\
\hline
\end{tabular}

\begin{tabular}{|c|c|c|c|c|c|}
\hline \multirow{3}{*}{$\begin{array}{l}\text { آزمون آمارى } \\
\text { p-value }\end{array}$} & & \multicolumn{4}{|c|}{ جدول f: نمره عزت نفس دانش آموزان دختر نوجوان قبل و بعد از مداخله در كروه آزمون و كنترل } \\
\hline & كنترل & & آزمون & & \\
\hline & انحر اف معيار & 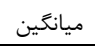 & انحراف معيار & ميانگَين & 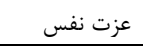 \\
\hline 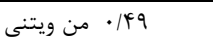 & N/Ar & $r \Delta / \cdot \Delta$ & $9 / 1$ & $r T / \Delta Q$ & 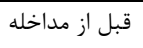 \\
\hline | •••• آناليز كوواريانس & N/9r & TF/TK & $9 / 91$ & TV/VF & بعد از مداخله \\
\hline
\end{tabular}

خلقوخوى، بىقرارى، بى ثباتى، كاهش اعتمادبهنفس، نافرمـانى از

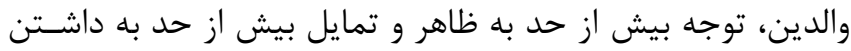

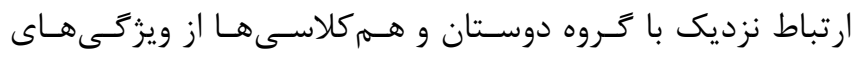

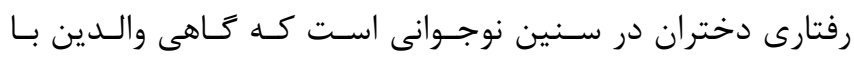

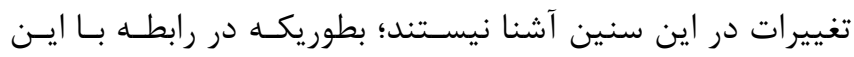

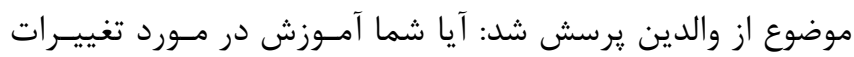

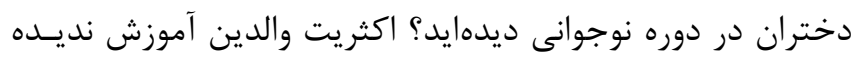

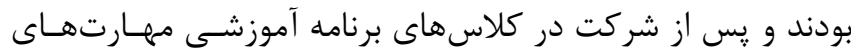

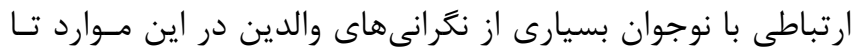

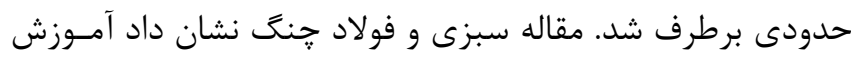

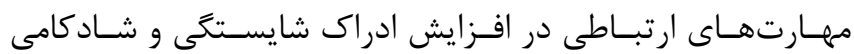

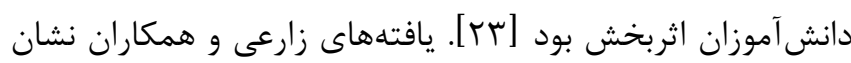

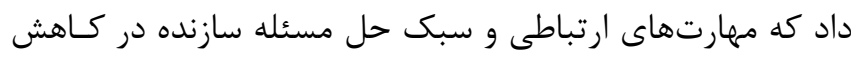

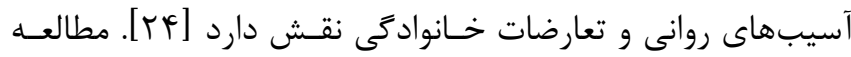

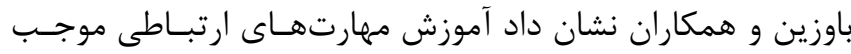
افزايش خودكارآمدى تحصيلى و كاهش ترس اجتماعى در دختران

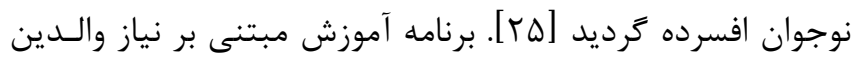

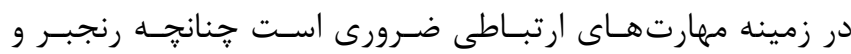

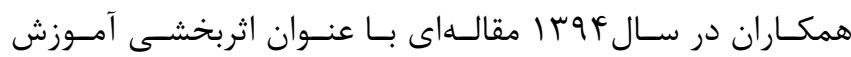

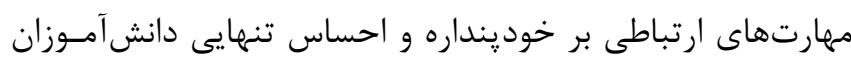

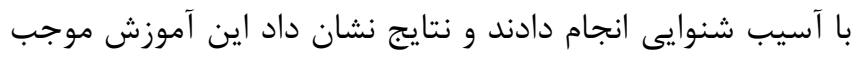

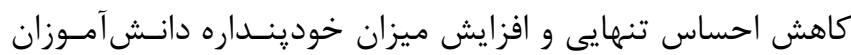

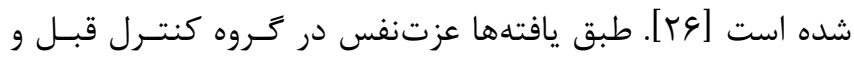

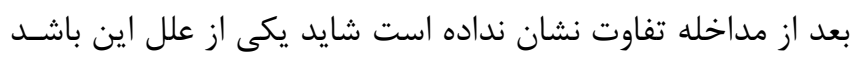

\section{بحث و نتيجه تيرى}

نتايج يزوهش حاضر نشان داد برنامه آموزش مهارتهاى ارتبـاطى دئى

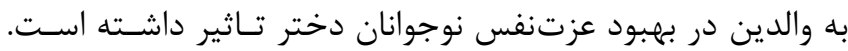

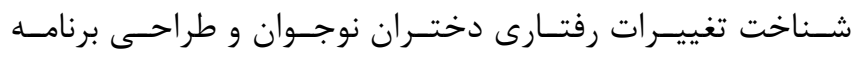

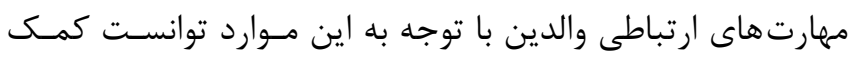

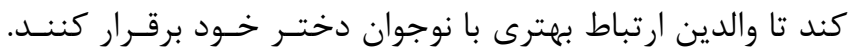

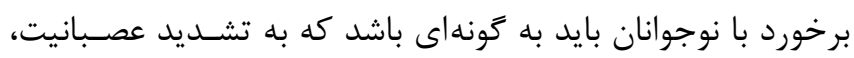

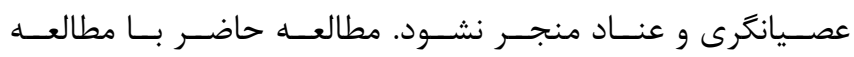

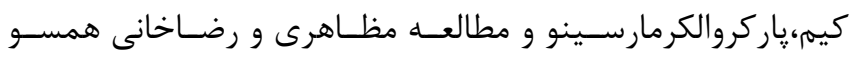

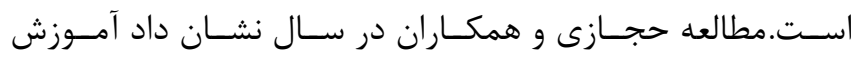

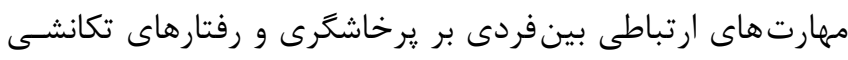

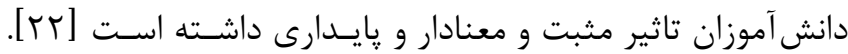

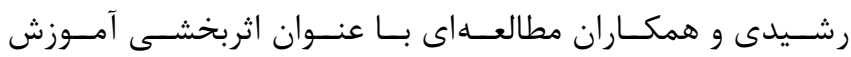

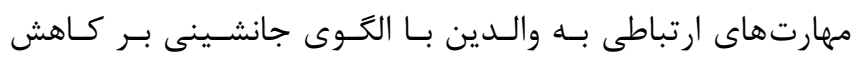

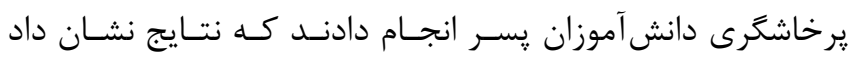

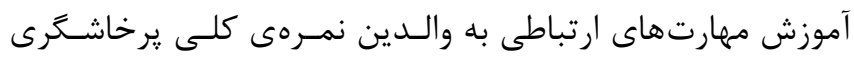

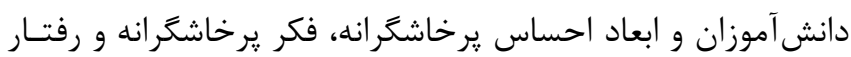

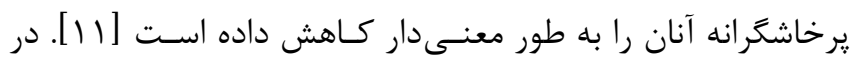

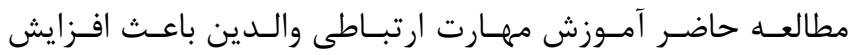

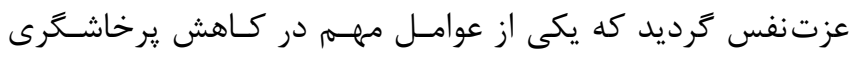

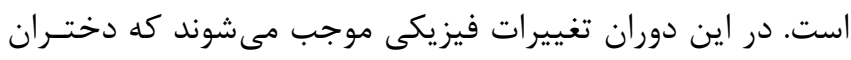

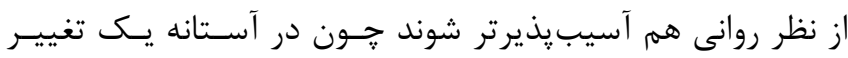

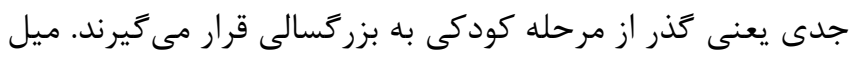

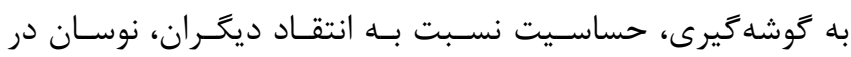


مطالعه باوزين و همكاران در سال نشان داد آمـوزش مهـارتهـاى

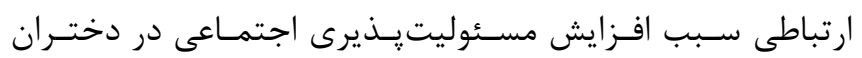

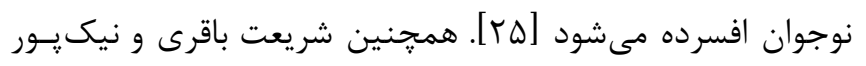

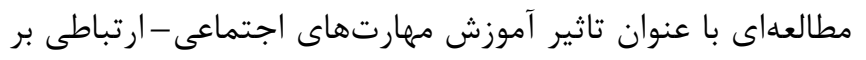

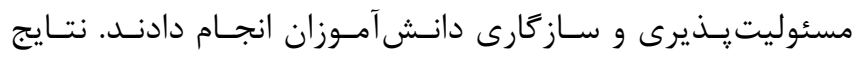

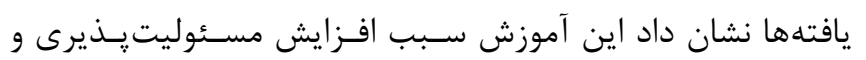

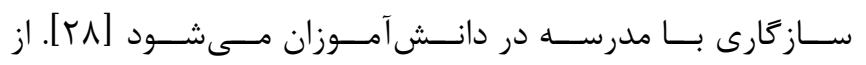

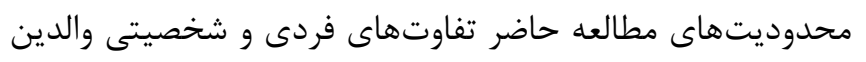

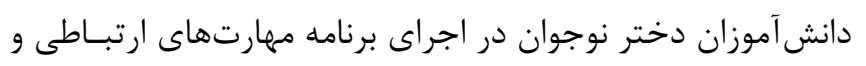

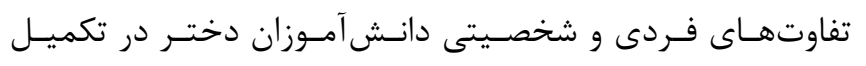

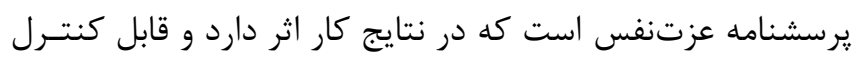

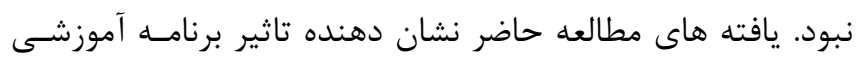

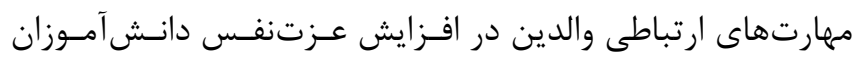

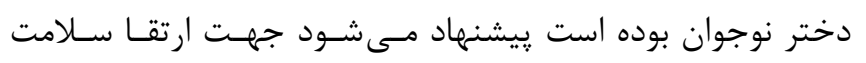

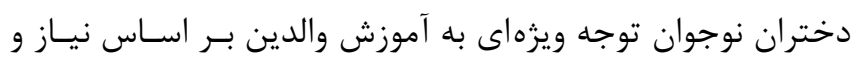

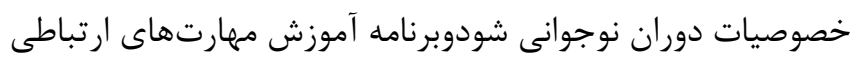

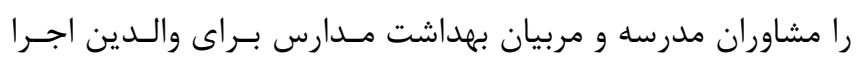
نمايند.

\section{سمم نويسند} نر كَس نصيرىنيا: طراحى مطالعـه. جمـع آورى دادهـــا، نحَـارش و وير ايش مقاله ربابه معماريان: مشاركت در طراحى مطالعه، مديريت اجراى طرح، وير ايش مقاله على وكبر راسخى: تجزيهوتحليل مقاله آمارى، ويرايش مقاله

\section{تشكر و قدردانى}

اين مقاله از بايان نامه دانشجوى كارشناسى ارئ ارشد يرستارى سلامت

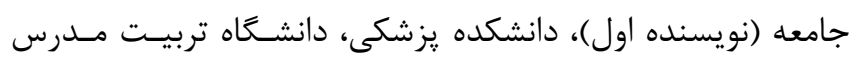

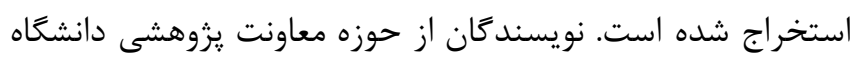

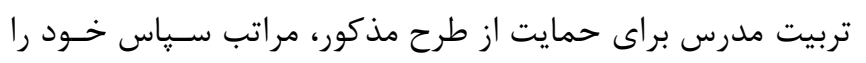

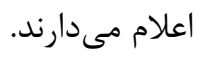

\section{منابع}

1. Kohandani A, Shirazi F, Asgari F. Adolescence and its relation to identity crisis. International Conference on Psychology and Culture Life 2015;1-14 [Persian]

2. Esmaielzadeh H, Asadi M, Miri M, Keramatkar M. Prevalence of High Risk Behaviors Among High

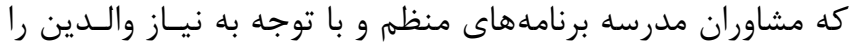

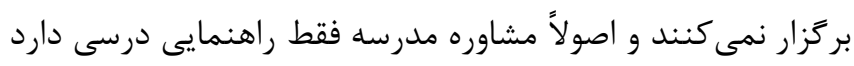

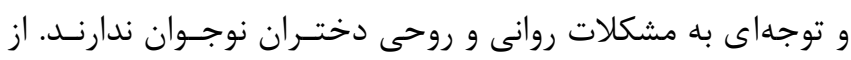

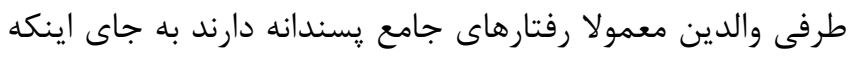

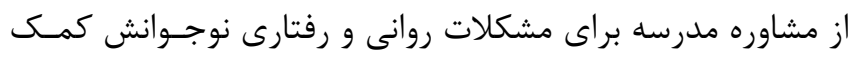

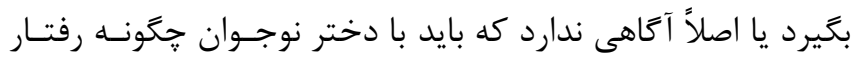

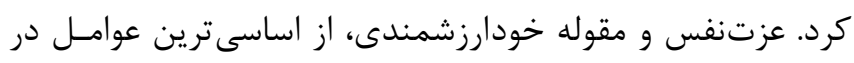

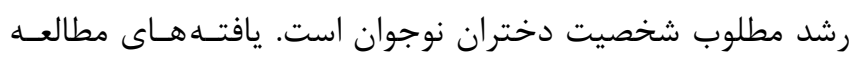

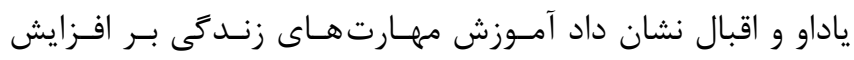

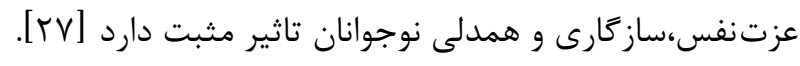

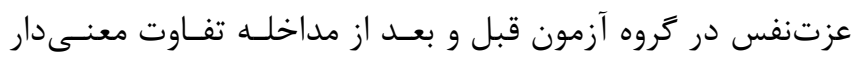

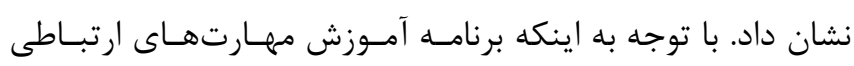

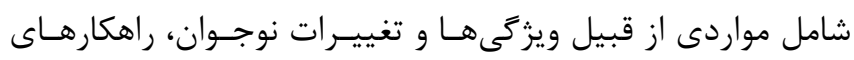

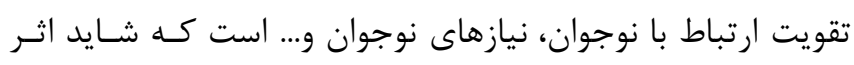

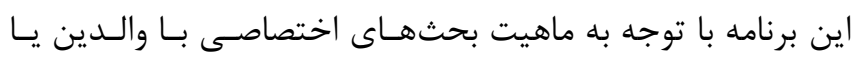

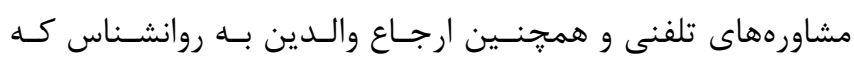

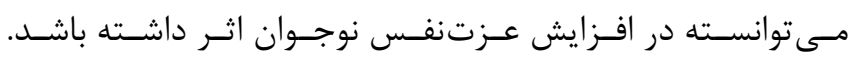

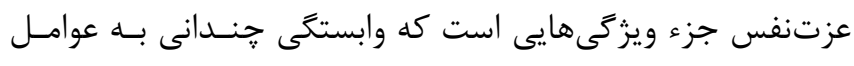

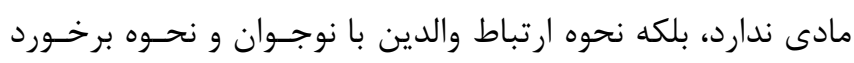

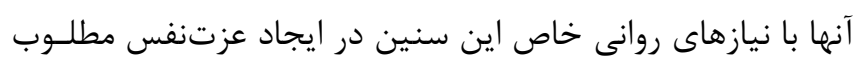

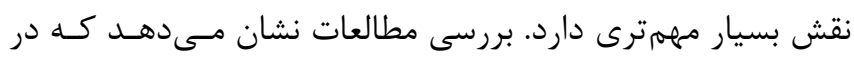

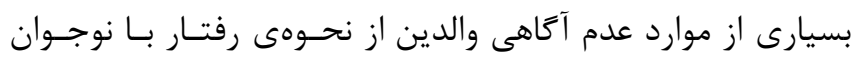

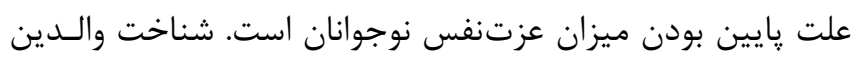

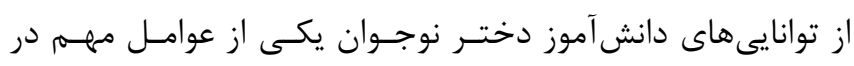

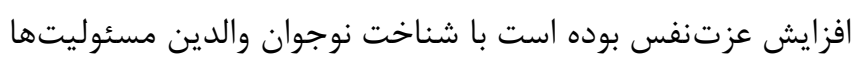

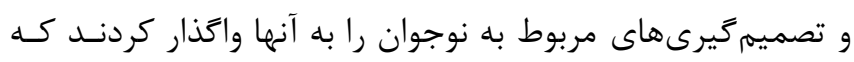

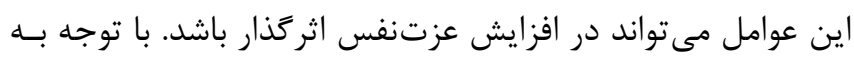

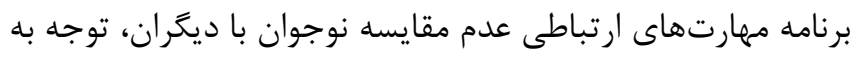

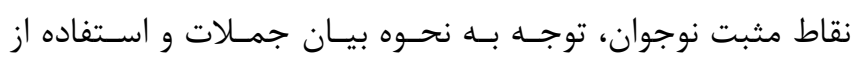

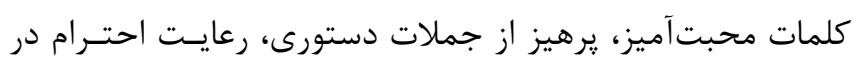

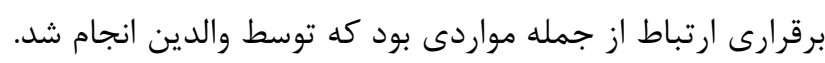

School Students of Qazvin in 2012. Iranian Journal of Epidemiology 2014; 10:75-82 [Persian]

3. Rezaie E, Alizadeh KH. The Comparison of Risky Behavior, Communication Skills and Self-Efficacy between Adolescents of Orphanage, Replacement 
Families and Normal Families in Bandar Abbas. Nursing education 2017; 6:54-61[Persian]

4. Moharreri F, Soltanifar A, Khalesi H, Eslami N. The Evaluation of Efficacy of the Positive Parenting for Parents in Order Improvement of Relationship with Their Adolescents. Medical Journal of Mashhad University of Medical Sciences 2012; 55:116-123 [Persian]

5. Parvizi S, Ahmadi F, Nikbakhtnasrabadi A. . The Golden Triad of Family-Adolescent Health. Psychology 2006; 10:250-257 [Persian]

6. Ahmadi MS, Hatami H, Ahadi H, Asadzadeh H. A Study of the Effect of Communication Skills Training on the Female Students' Self-efficacy and Achievement. Managment 2014;4:105-18[Persian]

7. Pummanee T, Tedla Y. Riesch S. Barriers to the Quality of Parent-Adolescent Communication in Thailand: An Ecological System Analysis. International journal of child development and mental health $2018 ; 6: 87-101$

8. Hoseini F, Sanaei B , Pourhosein R, Kraskian A. Qualitative Meta-analysis of Scientific Articles on Parent-Adolescent Intraction Psychology. Rooyesh-eRavanshenasi Journal 2017; 6:63-94] Persian]

9. Moitra T، Mukherjee I. Parent - Adolescent Communication and Delinquency: A Comparative Study in Kolkata, India. Europe's Journal of Psychology 2007; 8: 74-94

10. Mazaheri A, Rezakhani S. The Effectiveness of Communication Skills Training on the Increase of Self-Esteem and Decrease of Parent-Child Conflicts among Female High School Students. Educational Systems Research 2017;37 :131-149[ Persian]

11. Rashidi J, Khodadadisangdeh J, Rezaeiahvanoei M. The Effectiveness of Parenting Communication Skills Training with Substitution Learning Patterns on Aggression Reduction in High School Male Students. Health breeze 2016;5:26-32 [ Persian]

12. Rawatlal N، Kliewer W، Pillay B. Adolescent Attachment, Family Functioning and Depressive Symptoms. Psychiatr 2015;21:80-85

13. Kheirkhah M, Mokarie $H$, Nisanisamani L , Hosseini F. Relationship between Anxiety and Selfconception Female Adolescents. Iran Journal of Nursing 2013; 26 :19-29 [Persian]
14. Sharifi K, Masoudi-Alavi N, Tagharrobi Z, Sooki Z, Asgarian F,Akbari H. Relationship between Mothers' and Daughters' Self-esteem. Journal of Kashan University of Medical Sciences2011;15:352358 [Persian]

15. Babaei M, Fadakar Soghe R, Sheikhol-Eslami F, Kazemnejad Leili E. Survey self esteem and its relevant factors among high school students. Journal of Holistic Nursing and Midwifery 2015; 25:1-8] Persian]

16. Kim H, Parker, J. G, Marciano, A. R. W. Interplay of Self-esteem, Emotion Regulation, and Parenting in Young Adolescents' Friendship Jealousy. Journal of Applied Developmental Psychology 2017; 52: 170-180

17. Ziaei T, Gorji MG, Behnampour N, Rezai M. Mothers and Their Teenage Daughters' Perspectives on the Relationship Between Them. Research Development in Nursing \& Midwifery 2018; 15:2834 [Persian]

18. Bavazin F, Sepahvandi MA, Ghazanfari F. The Effectiveness of Communication Skills Training on Social Responsibility of Depressed Adolescent Females. Nursing Education 2018;7:48-58 [Persian].

19. Mostaghimi M, Shafi Abadi A. The Effectiveness of Communication Skills Training on Self-Esteem of 13 to 15 Year Old Girls in Welfare. Psychological Methods and Models 2013;3:17-30 [Persian]

20. Ahmady M. The Impact of Religion _Based Communication Skills on the Improvement of SelfEsteem and Mental Health among Students. Advances in Medical and Biomedical Research 2014; 22:13-22 [Persian]

21. Fathi Ashtiani, A. Psychological tests: Evaluation of Personality and Mental Health. $1^{\text {st }}$ Edition, Be'sat, Iran، Tehran، 2016 [ Persian]

22. Hejazi E, Babakhani N, Ahmadi N. The Effectiveness of Interpersonal Communication Skills Training on Aggression and Impulsive Behaviors among High School Students. Educational Systems Research 2018;12:25-38[ Persian]

23. Sabzi،N،FouladChang، M. The Effectiveness of Communication Skills Training on Perceived Competence and Happiness of Male Students in the Sixth Grade of Elementary School in Shiraz .Knowledge and Research in Psychology 2019;19:114-123 [Persian] 
24. Zarei ، E، Mirzaei، M، Sadeghifard، M. Providing a Model to Determine The Role of Communication Skills and Problem Solving Skills in Preventing from Mental and Social Damages by Mediated Family Conflicts. Culture of Counseling and Psychotherapy 2018;35:1-26 [Persian]

25. Bavazin F ,Sepahvandi MA, Ghazanfari F. The Effectiveness of Communication Skills Training on Academic Self-efficacy and Social Phobia in Adolescent Females with Depression. Psychiatric Nursing 2018;6:48-56 [Persian]

26. Ranjbar J, Tarkhan M, Taher M, Khanzadeh H, Eisapour A. The Effect of Communication Skills Training on the Self-Concept and Loneliness of
Students with Hearing Impairment. School Psychology 2016;4:39-54 [Persian]

27. Yadav, $P$ ، Iqbal, N. Impact of Life Skills Training on selfesteem,Adjustment and Empathy among Adolescents. Indian Academy of Applied Psychology 2009; 35:61-70

28. Shariat Bagheri M, Nickpour F. The Effect of Teaching Socio-Communicative Skills on Accountability and Adaptation with School in Students.Psychological Methods and Models 2018;32:203-220 [Persian] 